ÁREA ABIERTA. Vol.13. $n^{\circ} 3$. Noviembre 2013.

http://dx.doi.org/10.5209/rev_ARAB.2013.v34.n3.43353

Referencia: AA34-3.1211.172

"LA TRANSICIÓN POLÍTICA EN LIBIA: UN ANÁLISIS DESDE

LOS PERIÓDICOS DE REFERENCIA EN ESPAÑA"

AUTORA: María del Mar SORIA IBÁÑEZ

Universidad de Málaga. España

\title{
La transición política en Libia: un análisis desde los periódicos de referencia en España
}

\author{
Political transition in Libya: \\ an analysis of \\ the main Spanish newspapers
}




\title{
RESUMEN:
}

El conflicto de Libia ha sido una de las manifestaciones de mayor alcance de las reivindicaciones que se desarrollaron en el marco de la Primavera Árabe. El conflicto libio ocupó también numerosas portadas de periódicos en España y, por primera vez, se percibe que hay cierta unanimidad en el tratamiento informativo sobre la crisis. Por ello, esta investigación realiza un exhaustivo análisis de contenido de los periódicos de referencia nacional para determinar que se llevó a cabo una cobertura mediática extensa, basada en la defensa de los derechos fundamentales de la población libia, tras cuarenta años bajo un mandato dictatorial. Los principales resultados demuestran que el tratamiento mediático y su discurso estuvieron encaminados a la protección o defensa de la población civil y que la neutralidad en el enfoque fue la tónica general para reflejar los enfrentamientos entre insurgentes y fuerzas gadafistas. En definitiva, se comprueba que los medios se posicionan con el colectivo insurrecto.

\section{Palabras clave:}

Libia, tratamiento mediático, prensa española, comunidad internacional, Derechos Humanos.

\begin{abstract}
:
The conflict in Libya was one of the manifestations of greater scope among movements that were developed in the context of the Arab Spring. The Libyan conflict was also the headline in numerous covers of newspapers in Spain and for the first time, we perceive that there is unanimity in the media coverage of this crisis. Using a content analysis methodology this article focuses in Spanish national newspapers and concludes that they conducted an extensive media coverage, with the purpose of defending the fundamental rights of the Libyan population, after forty years of dictatorship. The main results of our research show that the discourse of the media was aimed at the protection and defence of the civilian population, and that neutrality in the approach was the general tone to reflect the clashes between insurgents and allies of Gadafi. In short, it proves that media are positioned with the rebel group.
\end{abstract}

\section{Key words:}

Libya, media coverage, Spanish press, international community, Human Rights 


\section{Introducción}

El 17 de diciembre de 2010 fue una fecha que marcaría un antes y un después en muchos países árabes gobernados tradicionalmente por sistemas autoritarios. Un joven de 26 años se inmoló ante una multitud de personas en Túnez para protestar por el sistema político discriminatorio y dictatorial imperante. Después, países vecinos como Argelina, Jordania, Egipto, Libia o Yemen se unieron a una serie de revueltas que, acaecidas durante la primera parte del año 2011 , recibieron el nombre de "Primavera Árabe".

En este contexto, fue destacable el caso de las revueltas populares en Libia, un país gobernado por el dictador Muamar Gadafi durante más de cuarenta años. Todo ocurrió en el mes de febrero, cuando se desencadenaron numerosos enfrentamientos entre la población civil que, por primera vez en la historia del país, salía a la calle para reclamar sus derechos. La insurrección del pueblo pronto organizó en el llamado Consejo Nacional de Transición cuyo brazo armado, el Ejército Popular Libio, protagonizó la revolución contra el régimen autoritario; sus máximos apoyos fueron militantes desertores y voluntarios civiles.

Sin lugar a dudas, el caso de Libia es muy diferente al de cualquier otro país implicado en la llamada "Primavera Árabe". El hecho de que los enfrentamientos derivaran en una guerra civil", así como la intervención de agentes internacionales como la OTAN o las Naciones Unidas, nos obligan a realizar una revisión del conflicto internacional de una manera más precisa. Así, Llaó (2011: 35) matiza lo siguiente:

"El desarrollo del conflicto en Libia, que degeneró con sorprendente inmediatez en guerra civil y posterior intervención militar de la OTAN bajo el mandato de la ONU, nos hace intuir diferencias sustanciales con el resto de los procesos de revueltas en el mundo árabe"

La guerra de Libia se convirtió en un fenómeno histórico que marcaría un antes y un después en el país. Es por ello que su presencia mediática a nivel internacional fue paralela a la sucesión de acontecimientos. Así, y durante los ocho meses que duró el enfrentamiento entre las tropas de Gadafi y la comunidad rebelde, numerosas portadas en todo el mundo se hicieron eco de un conflicto en el que intervinieron otros países a través de la OTAN. The Guardian (Jack, 2011) dedicó una noticia al revuelo mediático generado en torno al conflicto:

"TV coverage of the Libyan crisis is just a snapshot. We need to know more. The conflict in Lybia is dominating the news. And yet most of us know so little about the country"

Se puede decir que la importancia que adquirió Libia en los medios de comunicación podría ser comparable con la repercusión que también tuvieron los cruentos conflictos de Irak o de los Balcanes, y que también han sido repasados a través de diversas

\footnotetext{
${ }^{1}$ Lo que en un principio fue una guerra final, rápidamente se convirtió en conflicto internacional por la entrada de la OTAN y la consecuente implicación de la comunidad internacional
} 
investigaciones. Así, podemos hacer referencia a los análisis de Robertson (2004), Murray et al. (2008) o Aday (2010), que realizan una observación sobre la presencia mediática del conflicto de Irak tanto en prensa como en televisión. De igual modo, y dada la repercusión e implicación de la comunidad internacional en el conflicto de Los Balcanes, las investigaciones de Nohrsted et al. (2000) o las de Grundmann, Smith y Wright (2000) también llevaron a cabo un repaso por el tratamiento informativo que realizó la prensa de diferentes países; tampoco se olvidaron estos autores de estudiar y poner de manifiesto la importancia de la propaganda que realizaron los medios sobre este último conflicto.

Dicho lo anterior, no cabe duda de que el tratamiento informativo en torno al conflicto de Libia resulta sumamente interesante. Pese a que, como ya se ha comentado, existen numerosas investigaciones sobre otros conflictos en los que intervinieron todos los agentes internacionales, poco o casi nada sabemos aún del protagonismo que adquirió la guerra civil de Libia en los periódicos.

Sin embargo, y pese a que aún hay poca literatura sobre el enfoque mediático del conflicto, las voces más críticas ponen el acento sobre la ausencia de espacios mediáticos en favor de los derechos humanos inexistentes, como en cualquier conflicto internacional. La población civil volvió a ser el blanco y, una vez más, las ONG, la opinión pública y los medios de comunicación se quedaron al margen de la defensa de la ciudadanía o de la denuncia de las atrocidades (Fernández, 2011:78; Querejazu, 2011). Manso (2011: 42) va más allá y explica:

"Los medios de comunicación nos la siguen mostrando como si se tratara de una guerra diferente a la de Irak, ya que ha sido respaldada por la ONU; así, en una encuesta realizada en nuestro país, el $60 \%$ de los españoles apoyaba la intervención en Libia; sin embargo, otros piensan que la diferencia está en que con ese respaldo lo que se pretende es dividir en más partes el suculento botín, y que no se lo quede sólo EEUU".

Sorprende, además, que diversos expertos en la historia y el contexto sociopolíitico de Libia se adelantaran a los acontecimientos y vaticinaran la revolución. El monopolio dictatorial, la repentina apertura al exterior y la negociación, y la riqueza del petróleo, al que la comunidad internacional tenía poco acceso, fueron los detonantes de una crisis muy criticada por la mayoría de las voces académicas. En este sentido, Amirah (2006:8) ya auguró consecuencias de las reformas políticas concentradas en la unanimidad de la voz de Gadafi: "Podría parecer que Libia está viviendo una revolución. La pregunta es si hay suficientes revolucionarios para llevarla a cabo hasta el final". Y la hubo. En efecto, la revuelta fue una realidad como consecuencia de los cambios económicos y políticos desarrollados por un dictador que tenía control absoluto del petróleo de la rica Libia. Una premisa que también mantiene Kausch (2010), quien también vaticinó el desastre de la guerra debido a un "arbitrario" modo de negociar con Occidente. 
Por otro lado, y si nos centramos en el papel de España, además, debemos tener en cuenta que el asunto adquiere una gran importancia. España intervino en el conflicto prestando su apoyo a la OTAN y también ofreció las bases de Rota y de Morón para frenar la ofensiva de Gadafi².

Así, y dado el alto grado de implicación de España en la guerra civil de Libia, no podemos obviar que su protagonismo en los medios de comunicación también fue importante. Durante ocho meses, la prensa española dedicó numerosas portadas a todos los acontecimientos que giraban en torno a la intervención en Libia. Además, y con el casi total apoyo de la opinión pública, las diferentes informaciones emitidas desde España y por diferentes medios de comunicación se unificaban bajo un mismo criterio: el fin de Gadafi.

Esta premisa marcó la agenda setting de la prensa española durante ocho meses. Tiempo más que suficiente para analizar un discurso mediático que giraba en torno al establecimiento de unos derechos fundamentales con el apoyo al pueblo rebelde que gozaba de respaldo internacional.

Así, y bajo la premisa de que el apoyo de España al pueblo libio cobró un gran protagonismo en las portadas de los diarios, vemos necesario realizar un exhaustivo análisis en torno a esta causa. Al contrario de lo que sucedió en otros conflictos de índole internacional, en los que España participó con el envío de tropas -como ocurrió en Irak o en Afganistán³ - en Libia el apoyo se ejecutó desde el exterior y con un claro apoyo a la comunidad insurrecta. Se trató, en definitiva, de un apoyo justificado claramente por la lucha del establecimiento de los derechos humanos en Libia, condenada a una dictadura permanente al abrigo de Gadafi.

Y los medios de comunicación dieron buena cuenta de todo ello. La cobertura mediática fue notable aunque, siguiendo a los autores anteriormente mencionados y críticos con el enfoque informativo, podría haber estado más orientada a defender los derechos humanos de la población civil, y no fue el caso, pues las noticias se centraron en los capítulos cruentos del conflicto y en sus causas y consecuencias políticas.

El apoyo explícito del Gobierno español a la comunidad libia produjo una cobertura informativa con pocos precedentes. Los periódicos españoles trataron de manera unánime un conflicto que se generó por la lucha del establecimiento de los derechos fundamentales, y era necesario que la opinión pública se hiciera eco de todo ello.

\footnotetext{
${ }^{2}$ El 18 de Marzo 2011 el Gobierno de José Luis Rodríguez Zapatero anuncia públicamente el ofrecimiento de las bases de Rota (Cádiz) y de Morón de la Frontera (Sevilla) al dispositivo militar puesto en marcha por la comunidad internacional para frenar la ofensiva de Gadafi.

${ }^{3}$ Recordemos que el envío de tropas militares de España a Irak o Afganistán se justificó por la acción e incursión armada internacional que se desarrolló en ambos países. A diferencia de Libia, dónde se hacía necesaria la intervención de agentes externos para frenar la guerra civil, en los dos citados países la incursión de España, como la de otros agentes internacionales, se justificaba con el argumento de apoyar a EEUU en sus planes de combatir la construcción de armas de destrucción masiva (en Irak) o erradicar el terrorismo islámico (en Afganistán)
} 


\section{El enfoque del medio y el conflicto internacional}

Mucho se ha escrito sobre la idea de que la ideología del medio de comunicación e incluso el enfoque de su discurso condiciona la forma que adquiere la cobertura de un conflicto internacional. De hecho, postulados como los de Miller (2011) nos advierten que el modo en el que el medio de comunicación refleje episodios de violencia de cualquier conflicto será determinante para generar influencia en la opinión pública.

En la misma línea, y dependiendo del medio de comunicación del que hablemos, y del lugar geográfico en el que esté emplazado, también cambiará el enfoque informativo en torno a un episodio violento. De hecho, Catalbas (2011) y O'Regan (2010) realizan un repaso por el tratamiento informativo que realizan diferentes periódicos de Turquía 0 Irlanda en torno a las guerras de Irak y Afganistán. Por su parte, Erjavec y Volcic (2006) hacen lo propio en el caso del conflicto cróata y serbio. Todos estos estudios determinan que el origen y proyección de los diarios son factores que influyen en el tono que adquiere la información sobre conflictos bélicos.

Es por ello que también es importante señalar que el medio no solamente está condicionado por un enfoque -que, a su vez, depende de una línea editorial- o un origen, sino que también la influencia política condiciona su discurso. En este sentido, podemos señalar las aportaciones de Hartin y Human (2006) que demuestran que la ideología política determina la cobertura informativa de un determinado acontecimiento, además del enfoque que adquiere la información.

Es una realidad que cada medio de comunicación se marca su propia ideología y esto, sin lugar a dudas, condiciona su discurso (Popp, 2006). Por tanto, debemos hablar de una relación indiscutible entre el medio de comunicación y la política (Castells, 2008; Sabucedo, 1997; Colomé, 1994).

De igual modo, otro factor determinante en el enfoque que adquieren las informaciones de un determinado conflicto es el público al que se dirige. De hecho, varias investigaciones nos apuntan que la agenda setting depende en muchos casos no solamente de las pretensiones del medio de comunicación, sino también del público al que se dirige, y es por ello que en función del destinatario se segmentan de una forma $u$ otra los contenidos de las informaciones (López, 2004; Rubio, 2009; Zhu et al, 2006).

Dicho lo anterior, también resulta lógico afirmar que la objetividad periodística puede verse condicionada por la ideología del medio. Así, las aportaciones de Cooper (2009) o las de Glaser (1984) manifiestan que la objetividad en los medios de comunicación puede ser cuestionada por la propia visión del periodista en relación con el acontecimiento.

En el caso del tratamiento de conflictos internacionales, los estudios demuestran que la tendencia del discurso se orienta hacia diferencias en el tratamiento informativo sobre un determinado conflicto global. De hecho, los análisis de Robinson et al. (2009) sobre el reflejo de la guerra de Irak en diferentes medios de comunicación demuestran que, en 
efecto, cada diario ofrece un enfoque distinto en función de la ideología que condiciona al medio.

De igual modo, los análisis de Edy y Meirick (2007) también reflejan que hay diferencias en las informaciones de los distintos medios que repasaron las noticias en torno a la guerra de Afganistán. Los autores demuestran que, dependiendo del medio de comunicación que difunda una determinada información, el enfoque en el discurso es diferente.

\section{Hipótesis}

El objetivo principal de este estudio es analizar el apoyo unánime que prestaron los periódicos de referencia nacional en España a uno de los actores del conflicto: la comunidad insurrecta.

Por ello, esta investigación se orienta hacia la idea de que el "empoderamiento" justificado y necesario del pueblo libio y el apoyo explícito de España suscitó un gran interés informativo y los enfoques mediáticos en torno a ello fueron muy similares. Y es que diferentes investigaciones hacen referencia a que el empoderamiento ciudadano genera siempre notoriedad mediática y apoyos sociales y/o institucionales (Holtzhausen, 2005; Mitchell, 2006; Bandura, 1986).

Recordemos, pues, la hipótesis principal de esta investigación:

- RQ1: Los periódicos más importantes de España realizaron un tratamiento informativo unánime y el enfoque fue muy similar, apoyando al pueblo libio.

Esta idea nos lleva a plantearnos las siguientes cuestiones, que tienen que ver con el enfoque que adquirieron las informaciones en los medios de comunicación:

- H1: Hubo una cobertura informativa amplia y un apoyo unánime de los diarios de referencia españoles a las acciones del pueblo libio

- H2: La prensa nacional se hizo eco del conflicto de una manera neutral, mediante el uso de diversas fuentes informativas que enriquecen la información

- H3: El tratamiento informativo y gráfico se realizó de una forma ética, respetando los derechos fundamentales de las personas

\section{Metodología}

Bajo la perspectiva de que los medios de comunicación no son objetivos, y de que su agenda mediática y tratamiento informativo están condicionados por ciertos matices ideológicos (Canel, 1999), analizamos los cinco diarios españoles de referencia nacional. 
Para desarrollar la investigación nos basamos en la teoría del enfoque y en el análisis de contenido. Sobre la primera técnica, cabe destacar que son amplios y variados los estudios que hacen referencia al framing ideológico: la información está condicionada por las propias creencias (Canel, 1999).

En cuanto al análisis de contenido, podemos definirlo como una "técnica de investigación destinada a formular, a partir de ciertos datos, inferencias reproducibles y válidas que pueden aplicarse a su contexto" (Krippendorff, 1990: 28). Es decir, hablamos de un recurso de carácter cuantitativo que nos ayuda a obtener datos y extraer conclusiones de los mismos.

De este modo, nuestro análisis de contenido, que cubre también el enfoque de la información, se plantearía en torno a las siguientes cuestiones, que están directamente relacionadas con las hipótesis y objetivos de esta investigación. Se debe tener en cuenta que durante todo el análisis primará el fin de detectar si los periódicos de referencia nacional apoyaron de manera similar la revolución libia.

\subsection{Recopilación y obtención de resultados}

En cuanto al procedimiento de obtención de resultados, se ha hecho uso de diversas herramientas de análisis estadístico y ecuacional. Las principales herramientas serán usadas, a través de hojas de cálculo de datos, para obtener los resultados observados y muestreados del proceso previo de toma de datos. Haciendo uso del análisis estadístico más elemental, se obtendrán los resultados de valores medios y valores porcentuales sobre el total del muestreo de cada diario.

De dichos cálculos iniciales más básicos, podremos obtener los resultados en forma tabulada y en forma gráfica, que nos serán de gran ayuda a la hora de interpretar dichos resultados obtenidos.

Dando un paso más, se llegará a un análisis ecuacional más complejo y elaborado, puesto que se utilizará el cálculo de las regresiones por mínimos cuadrados, para ajustar una nube de datos medida y tener las líneas de tendencia. Por otro lado, ciertos datos podrán ser valorados con la distribución $X^{2}$ de Pearson usada en inferencia estadística, que es una distribución de probabilidad continua que será utilizada como prueba de independencia y como prueba de la bondad de ajuste y en la estimación de varianzas.

\subsection{Criterios de estudio}

Para alcanzar los objetivos propuestos se han analizado una serie de ítems que nos ayudan, de manera paralela, a corroborar las hipótesis marcadas. 
1. Las informaciones de los periódicos presentan un enfoque informativo muy similar y de apoyo a la insurrección. Mediante este ítem determinaremos cuestiones referidas a si se habla de la comunidad en un sentido peyorativo o si se legitima la acción del colectivo insurrecto.

2. Los medios de comunicación no estuvieron condicionados por su ideología y se priorizó la difusión de la información de una manera más o menos objetiva. Este criterio nos servirá para saber si hay pluralidad de enfoques y géneros periodísticos y si las informaciones tienen fuentes diversas y contrastadas.

3. El tratamiento informativo y gráfico se realizó de una forma ética, respetando los derechos fundamentales de las personas. Mediante esta cuestión podremos determinar si hay presencia de ética periodista mediante el respeto a la imagen de las personas o a las víctimas de la guerra civil Libia.

\section{3. "Corpus" de estudio}

Para elaborar el análisis de contenido, nos hemos basado en el estudio de las informaciones aparecidas en prensa. Hemos seleccionado los cinco periódicos de referencia nacional en función del número de lectores. Para ello, nos hemos basado en el análisis del EGM (Estudio General de Medios) ${ }^{4}$ que refleja el número de lectores de prensa diaria en España. Basándonos en el citado estudio, nuestro análisis se centrará en los siguientes diarios nacionales de referencia:

\begin{tabular}{|l|c|}
\hline NOMBRE DEL PERIÓDICO & NÚMERO DE LECTORES DIARIOS \\
\hline EI País & 1.961 \\
\hline EI Mundo & 1.205 \\
\hline La Vanguardia & 846 \\
\hline El Periódico de Cataluña & 770 \\
\hline ABC & 698 \\
\hline
\end{tabular}

\section{Un conflicto internacional en la prensa española: Libia}

Como ya se ha matizado, no cabe duda alguna de que un conflicto internacional siempre condiciona la agenda setting de un medio, o bien es éste el que queda supeditado a determinados intereses que pueden integrar el acontecimiento noticioso (Alessandri, 1996; González San Ruperto, 2001).

\footnotetext{
${ }^{4}$ El EGM realiza tres estudios anuales sobre las tendencias de los lectores españoles. En el caso de nuestra investigación, nos hemos basado en el análisis que comprende los meses desde octubre de 2010 hasta mayo de 2011.
} 
Sin embargo, también es cierto que, desde una visión más objetiva, cercana a la ética periodística, podemos confiar en la teoría de que los medios de comunicación pueden ejercer como mediadores en situaciones de conflicto y defender el establecimiento de los derechos humanos mediante el amparo neutral a las víctimas de las consecuencias de los conflictos.

Sin embargo, los estudios vigentes demuestran que el tratamiento informativo en torno al conflicto siempre queda deformado por los condicionantes ideológicos del medio, aunque ha habido esfuerzos individuales por determinar criterios de ética periodística en torno a conflictos internacionales de carácter armado (Velásquez, Gutiérrez, 2001: 91).

Los códigos deontológicos de la profesión periodística, que integran la importancia del conflicto internacional en la agenda de medios, reflejan claramente que el profesional de la información debe velar por el respeto de los derechos humanos en la difusión de las noticias. De una forma más concreta, la UNESCO fija que uno de los principios de la ética profesional del periodismo ha de estar basado en el respeto a los valores universales y la eliminación de las guerras.

Por tanto, y al hilo de lo anterior, podemos determinar que los organismos supremos de protección de los derechos fundamentales recomiendan que las informaciones sobre los conflictos internacionales fomenten la paz y la unidad de los pueblos.

Así, numerosos acontecimientos históricos han sido retratados a lo largo de la historia bajo unas premisas que quedan muy alejadas de los principios de la ética periodística. De hecho, la herencia mediática en torno al conflicto de los Balcanes o al olvidado genocidio en Ruanda evidencian, por un lado, que se trata de acontecimientos que ocupan numerosas portadas y que, por otro, no quedan reflejados adecuadamente. La realidad, en ambos casos, quedó supeditada a la visión del medio informativo (González San Ruperto, 2001; Sendín, 2006).

Ahora bien, si miramos hacia los conflictos internacionales contemporáneos, la reciente Primavera Árabe también ocupó numerosos titulares bajo condicionantes subjetivos. La cooperación, la ayuda humanitaria o la protección internacional de la población civil en casos como Siria o Libia raramente se convirtieron en portada.

Sin embargo, también podemos decir que el conflicto de Libia adquirió matices ligeramente diferentes en lo que al tratamiento informativo se refiere. Pese a que cada medio de comunicación utilizaría un enfoque según su línea editorial habitual, lo cierto es que 40 años de dura dictadura convirtieron esta guerra civil en un movimiento orientado hacia el cambio en el mundo árabe e islámico (Sacaluga, 2011; Moustaoui, 2011).

Dicho lo anterior, no cabe duda de que la crisis de Libia generaría un antes y un después en la historia de este país. La cobertura informativa internacional de este conflicto fue especialmente relevante a medida que se encrudecía la guerra. La idea del 
levantamiento del pueblo libio frente a un régimen opresor fue el concepto más repetido en los periódicos españoles.

De hecho, en el caso de España, los principales periódicos de referencia llevaron a cabo un seguimiento exhaustivo. Pese a que, se reitera, el enfoque variaba ligeramente según el medio, tenemos que apuntar que el interés mediático fue notable. Destaca, según nuestro análisis, el caso del periódico El Mundo, en el cual un 54\% de las portadas se dedicaron a la crisis de Libia durante los ocho meses que se prolongó el conflicto.

\section{GRÁFICO No 1}

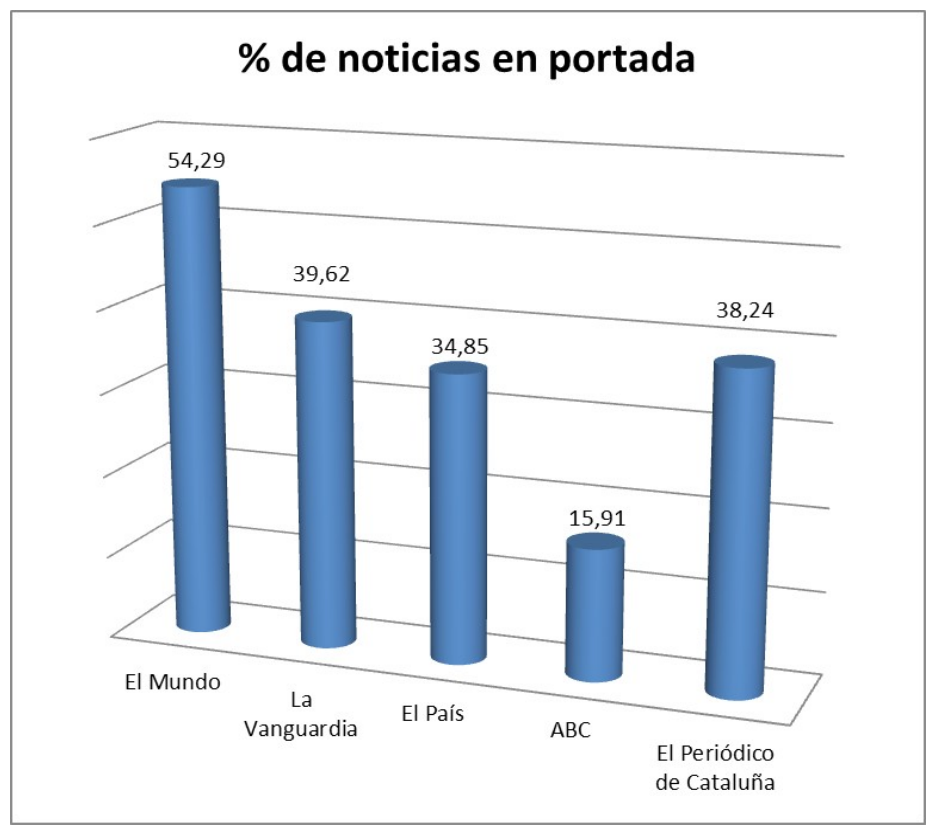

Por otro lado, y pese a que nuestro estudio demuestra que los principales periódicos españoles incorporaron a Libia en sus páginas, lo cierto es que hasta ese momento poco o casi nada ha trascendido por lo que respecta al tratamiento informativo del conflicto por parte de España, pese a que fue un país clave en materia de la intervención internacional.

Lo primero que podemos hacer notar es la cantidad de noticias diarias que aparecen en cada periódico utilizado en la investigación, en la que mostramos el abanico de la cantidad de noticias mostradas (gráfico $n^{\circ} 2$ ). Sin embargo, sí que podemos afirmar que la prensa introdujo algo más de dos noticias diarias en la sección de internacional. La Vanguardia destaca como la publicación diaria que mantiene esa media, seguida de El Mundo (gráfico $n^{\circ}$ 3).

Estos datos positivos coinciden con otras investigaciones sobre conflictos internacionales, en las que también se comprobó que las crisis de carácter armado tienen importancia en 
la agenda setting de la sección de internacional de los medios (Sendín, 2001: 224; García, 2002).

\section{GRÁFICO N²}

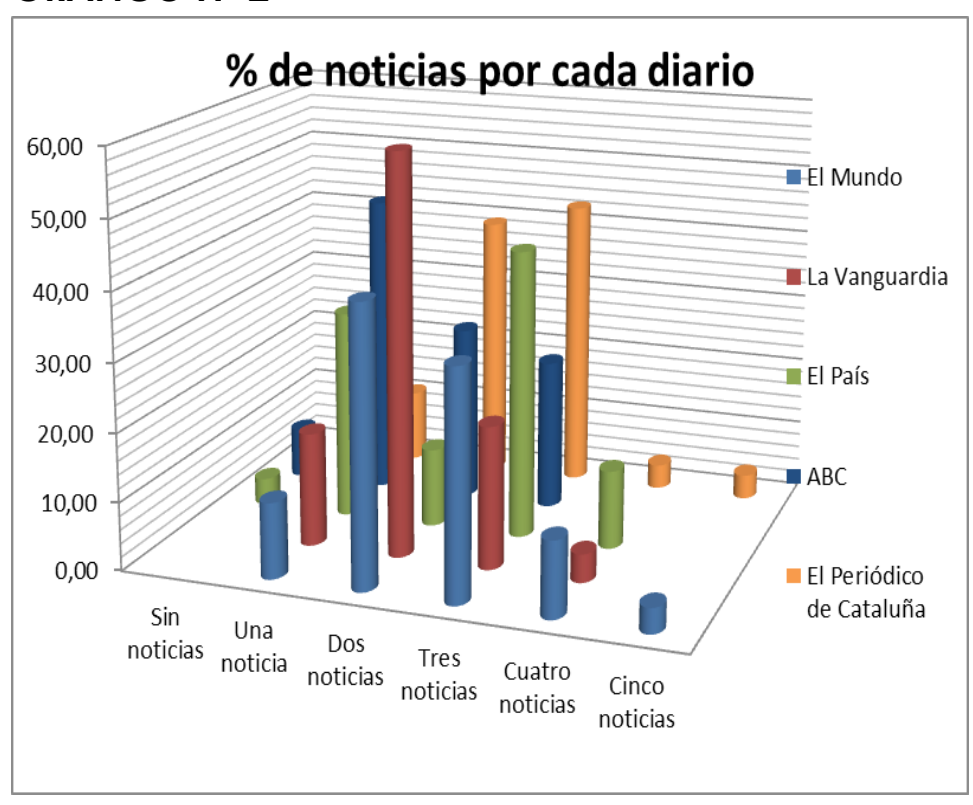

\section{GRÁFICO N 3}

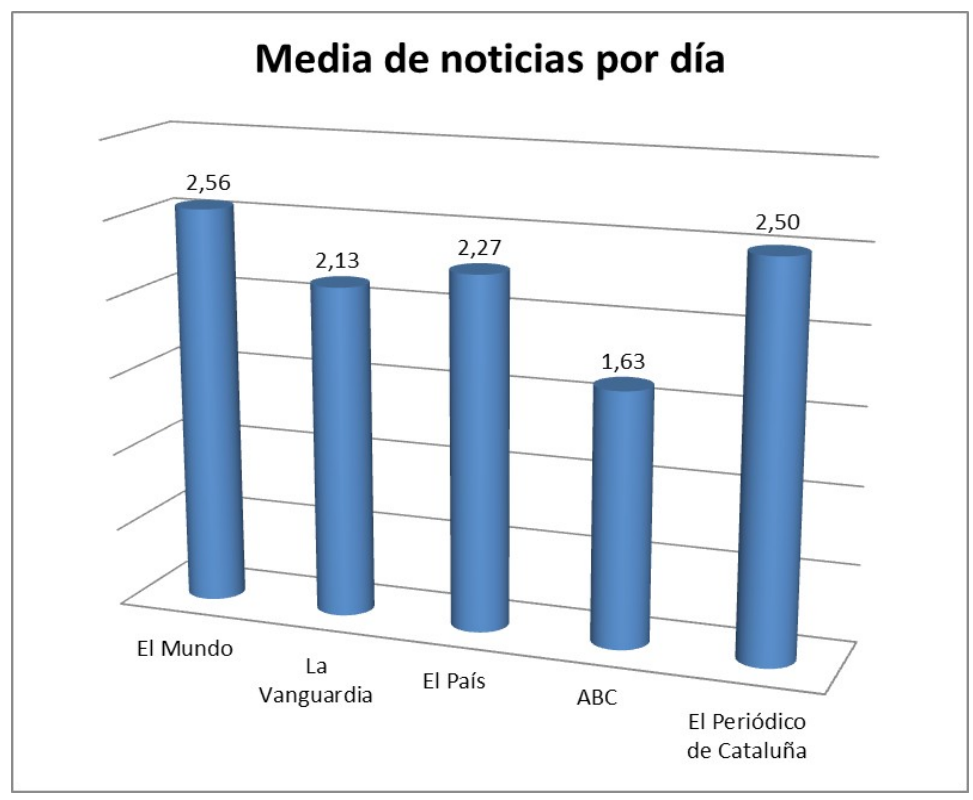

Por otro lado, y más allá del volumen de cobertura mediática que, en el caso que tratamos, adquirió el conflicto de Libia, el discurso informativo de esta crisis internacional vino determinado por las fuentes que avalaban ese enfoque. 
Al igual que en otras guerras, en ésta también hemos podido comprobar que la construcción de la noticia es diferentes según el medio informativo. Es por ello que el enfoque puede variar ligeramente dependiendo de la elección de la fuente. Sin embargo, no cabe duda de que la fuente principal que determinó la cobertura informativa de la crisis libia fueron los organismos internacionales que habían intervenido de una $u$ otra forma en el conflicto -fundamentalmente la OTAN y la ONU- (gráfico $n^{\circ} 4$ ). Y en este sentido, debemos matizar que ello contribuye a que la prevalencia de una única fuente determine un discurso unidireccional, que se puede alejar de la diversidad de realidades que puede atribuirse a un conflicto armado (García, 2002: 143; Aday, 2010).

\section{GRÁFICO No 4}

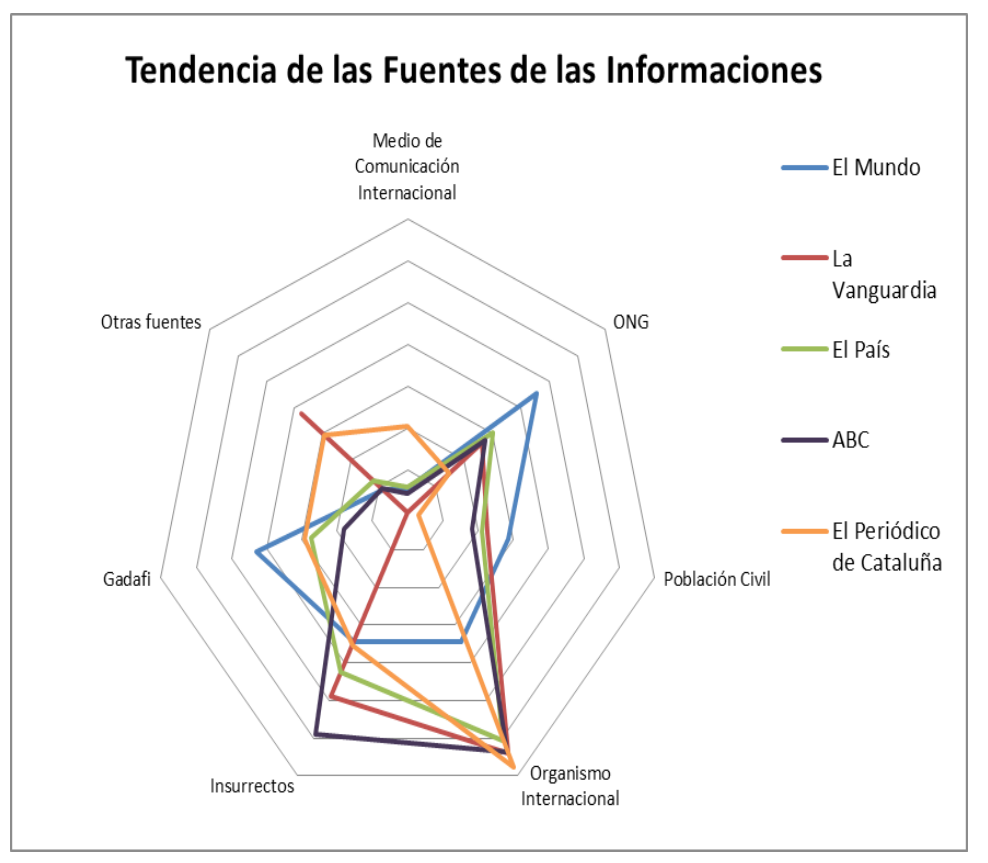

De este modo, nuestro análisis nos ha llevado a determinar que la tendencia general de los periódicos analizados ha sido la de recurrir a fuentes oficiales de carácter internacional para dar forma al contenido de la información, si bien es cierto que existen diferencias entre publicaciones periódicas en este sentido. Por ello, es destacable el hecho de que La Vanguardia sea el medio que ha hecho una mayor apuesta por utilizar a los insurrectos como fuente informativa, de la misma manera que también es sorprendente que ninguno de los periódicos haya realizado una clara apuesta por situar a la población civil como voz de la información (tabla $n^{\circ} 1$ ). Las ONG tampoco ocupan un lugar importante en la construcción informativa, pese a que participaron activamente desde el inicio del conflicto para proteger a la población civil víctima de los continuos ataques de las fuerzas armadas de Gadafi. 
TABLA No 1

\begin{tabular}{|l|c|c|c|c|c|}
\hline \% fuentes & EI Mundo & $\begin{array}{c}\text { La } \\
\text { Vanguardia }\end{array}$ & El País & ABC & $\begin{array}{c}\text { El Periódico } \\
\text { de Cataluña }\end{array}$ \\
\hline $\begin{array}{l}\text { Medio } \\
\text { Comunicación } \\
\text { Internacional }\end{array}$ & 2,86 & 0,00 & 3,03 & 2,27 & 10,29 \\
\hline ONG & 22,86 & 13,21 & 15,15 & 13,64 & 7,35 \\
\hline Población civil & 14,29 & 11,32 & 10,61 & 9,09 & 1,47 \\
\hline $\begin{array}{l}\text { Organismo } \\
\text { Internacional }\end{array}$ & 17,14 & 32,08 & 30,30 & 31,82 & 33,82 \\
\hline Insurrectos & 17,14 & 24,53 & 21,21 & 29,55 & 17,65 \\
\hline Gadafi & 21,43 & 0,00 & 13,64 & 9,09 & 14,71 \\
\hline Otras & 4,29 & 18,87 & 6,06 & 4,55 & 14,71 \\
\hline
\end{tabular}

A tenor de los datos presentados en la tabla anterior, se puede estudiar la tendencia y realizar un ajuste por mínimos cuadrados. Se podría obtener la ecuación de la línea de tendencia parabólica que mejor ajusta la nube de puntos que representan los datos anteriores. Así pues, tomaremos dos variables: "X" sería la variables discreta que tomaría los valores enteros de 1 a 7 (el 1 representaría a las fuentes de "Medios de Comunicación Internacionales" y el 7 a "Otras fuentes" según el orden de la tabla n 1) e "Y" que representaría el porcentaje numérico de dichas fuentes sobre cada periódico. Ha de decirse que no se obtiene una gran precisión y el error estaría en torno a una décima. De cualquier modo, puede obtenerse la ecuación del polinomio de grado 2 que se ajusta del mejor modo posible a toda la nube de puntos, que sería el siguiente:

$y=-2.4892 \cdot x^{2}+20.563 \cdot x-18.182$

Siguiendo con el discurso informativo que adquirió la guerra civil de Libia en los periódicos de referencia en España, nuestro estudio nos ha llevado a la conclusión de que, en términos generales, el enfoque de las informaciones no fue mayoritariamente positivo (tabla $n^{\circ}$ 2). De hecho, podemos decir que el contenido estuvo centrado en el número de víctimas mortales o en los ataques del dictador libio hacia los insurrectos. La tendencia general de las noticias fue la de destacar titulares como los siguientes: "Torturas fuera de control"; "Gadafi juega con la matanza"; "Guerra contra Gadafi".

Las diferencias entre los diferentes periódicos es poco relevante. De hecho, los cinco analizados coinciden en situar el porcentaje de noticias negativas entre un $52 \%$ y un $64 \%$; es decir, podemos afirmar que más de la mitad de las informaciones vertidas por todos los periódicos sobre el conflicto de Libia son negativas. 
Otras investigaciones sobre conflictos internacionales también pusieron de manifiesto la tendencia a hablar de la guerra de forma negativa, sin potenciar, en ningún caso, el mensaje informativo en torno a la paz (Serrano y López, 2008). No debemos olvidar, además, que en cualquier conflicto internacional intervienen agentes externos que luchan por el establecimiento de la paz y protegen a la población más vulnerable. Sin embargo, es muy poco habitual que se oriente la información hacia esta parte de los conflictos tan desconocida por la opinión pública.

\section{TABLA No 2}

\begin{tabular}{|l|c|c|c|c|c|}
\hline$\%$ & El Mundo & $\begin{array}{c}\text { La } \\
\text { Vanguardia }\end{array}$ & El País & ABC & $\begin{array}{c}\text { El Periódico } \\
\text { de Cataluña }\end{array}$ \\
\hline Tono negativo & 64.29 & 86.76 & 60.61 & 56.82 & 52.94 \\
\hline Tono neutro & 35.71 & 13.21 & 39.39 & 43.18 & 47.06 \\
\hline
\end{tabular}

Fuente: ver nota a pie de página $n^{05}$

Dicho lo anterior, nos centramos ahora en las referencias realizadas por los periódicos hacia los insurgentes. Así, se ha detectado que ha habido cierta tendencia a defender el levantamiento del pueblo libio contra el régimen dictatorial de Gadafi. Destacamos que $A B C$ ha sido la publicación que ha manifestado una mayor inclinación hacia este criterio, seguido por El Periódico de Cataluña (tabla n³).

También es importante destacar que en ningún caso se ha observado que haya críticas directas contra los insurgentes, aunque ha habido informaciones en las que no se les ha señalado. Es en estos casos en los que se habla de una "información neutra" sobre la comunidad de insurrectos, en el sentido de que no se realiza una reivindicación positiva directa sobre ellos.

\section{TABLA No 3}

\begin{tabular}{|l|c|c|c|c|c|}
\hline$\%$ & El Mundo & $\begin{array}{c}\text { La } \\
\text { Vanguardia }\end{array}$ & El País & ABC & $\begin{array}{c}\text { El Periódico } \\
\text { de Cataluña }\end{array}$ \\
\hline $\begin{array}{l}\text { Habla positivo } \\
\text { pueblo Llbio }\end{array}$ & 48.57 & 69.81 & 31.82 & 61.36 & 52.94 \\
\hline $\begin{array}{l}\text { Habla neutral } \\
\text { pueblo libio }\end{array}$ & 51.43 & 30.19 & 68.18 & 38.64 & 47.06 \\
\hline
\end{tabular}

Fuente: ver nota a pie de página $n^{0}{ }^{6}$

\footnotetext{
${ }^{5}$ Pearson $\chi^{2}: 30.484,4, p<.01$

${ }^{6}$ Pearson $\chi^{2}: 32.705,4, p<.01$
} 
En la línea anterior, y siguiendo con ese apoyo mayoritario que nuestro análisis ha detectado de los medios de comunicación hacia el pueblo libio, también debemos referirnos al modo de detección de este dato que nos lleva a tal afirmación.

De una manera más concreta, debemos señalar que hemos analizado tres palabras claves que, en el cuerpo de las informaciones de los diferentes periódicos, han servido para legitimar la acción del pueblo libio que se ha levantado contra Gadafi. Por ello, hemos contabilizado el número de veces que han aparecido los términos "derechos fundamentales", "democracia" y "libertad", todos ellos relacionados la insurgencia positiva, para los periódicos analizados, de la comunidad Libia.

Por tanto, resaltamos el dato de que El Periódico de Cataluña es la publicación que más apuesta por la defensa del establecimiento de un sistema democrático en Libia, sobre todo a través de la inclusión del término "derechos fundamentales", que también es el más reiterado por el resto de los periódicos.

Por el contrario, y aunque hemos visto que al menos la mitad de las informaciones realizan una clara defensa de la causa que defienden los insurrectos (gráfico n 5), encontramos también que hay hasta un $58 \%$ de noticias en el caso de La Vanguardia en las que no se hace referencia alguna a la defensa de los valores democráticos para la comunidad insurgente (tabla $n^{\circ} 4$ ).

Podemos determinar, a tenor de los resultados, que en general existe una postura neutra en torno a la legitimación de las acciones reivindicativas de la comunidad insurgente, puesto que en todos los periódicos nos encontramos con porcentajes en torno a las noticias que realizan una clara defensa hacia los insurrectos - a través de la inclusión de términos tales como "derechos fundamentales", "libertad" o "democracia-, así como de aquellas en las que no se hace referencia alguna a este aspecto.

\section{GRÁFICO N 5}

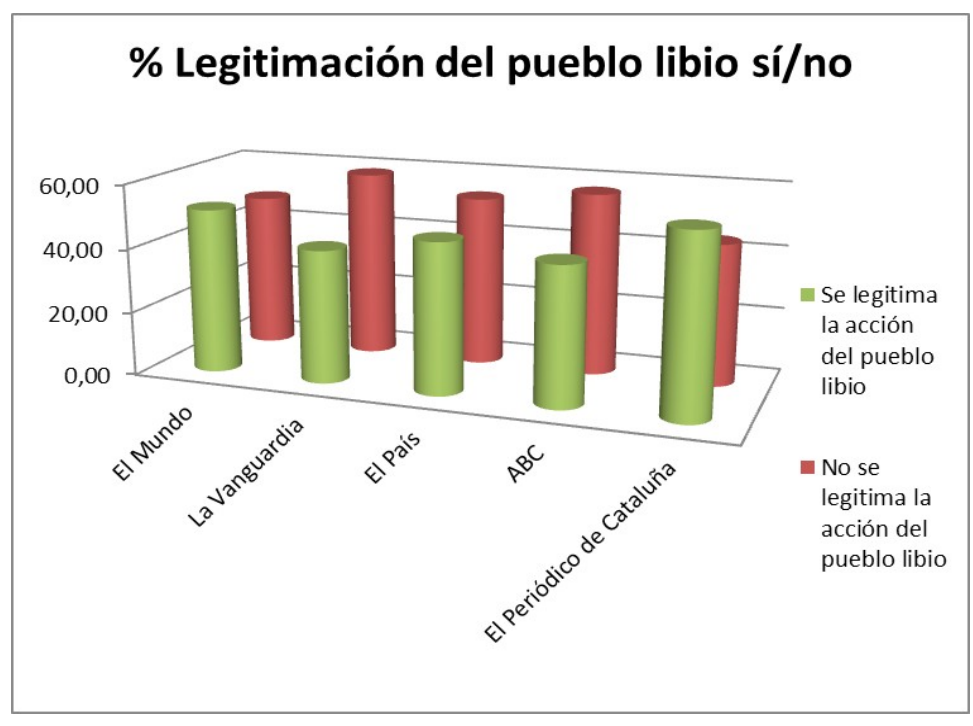


TABLA N 4

\begin{tabular}{|l|c|c|c|c|c|}
\hline$\%$ & El Mundo & La Vanguardia & El País & ABC & $\begin{array}{c}\text { El Periódico } \\
\text { de Cataluña }\end{array}$ \\
\hline $\begin{array}{l}\text { Derechos } \\
\text { Fundamentales }\end{array}$ & 31,43 & 35,85 & 16,67 & 25,00 & 38,24 \\
\hline Democracia & 18,57 & 3,77 & 28,79 & 13,64 & 7,35 \\
\hline Libertad & 0,00 & 1,89 & 1,52 & 4,55 & 10,29 \\
\hline
\end{tabular}

Fuente: ver nota a pie de página $n^{07}$

Por otro lado, y en lo que se refiere al enfoque que adoptan las distintas publicaciones sobre la acción de las fuerzas gadafistas contra la comunidad insurgente, se ha detectado que el análisis mediático también es medianamente neutral. Es decir, aunque existe un mayor número de noticias que critica el régimen de Gadafi, también se vierten informaciones en las que no se hace referencia alguna a los ataques del dictador hacia la comunidad Libia.

\section{GRÁFICO N 6}

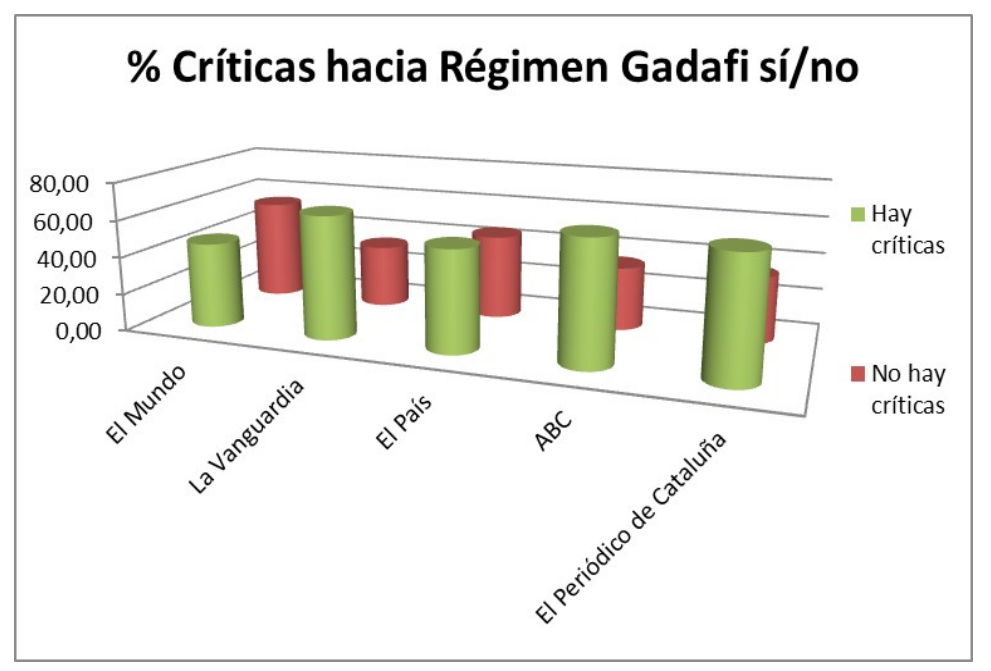

Para referirnos a los discursos analizados en torno a las críticas de los periódicos hacia la acción de Gadafi, hemos analizado la presencia de los términos "represión", "genocidio" y "dictador", altamente relacionados con la postura del dictador libio durante los ocho meses de guerra civil.

Por tanto, y tal y como se puede apreciar en la tabla $n^{\circ}$ 5, despunta la inclusión de la palabra "represión" en el periódico La Vanguardia, como la más reiterada para hacer alusión a la acción del dictador, siempre en detrimento de los insurgentes y, por ende, de la población civil, la más afectada por la crisis Libia. Además, también es destacable la

${ }^{7}$ Pearson $\chi^{2}: 50.956,8, p<.01$ 
aparición del término "dictador", que llega a alcanza casi el 50\% de las informaciones sobre la guerra civil de Libia en el diario El País.

\section{TABLA N ${ }^{\circ} 5$}

\begin{tabular}{|l|c|c|c|c|c|}
\hline$\%$ & El Mundo & La Vanguardia & El País & ABC & $\begin{array}{c}\text { El Periódico } \\
\text { de Cataluña }\end{array}$ \\
\hline Represión & 21,43 & 77,36 & 46,97 & 34,09 & 35,29 \\
\hline Genocidio & 17,14 & 33,96 & 12,12 & 20,45 & 16,18 \\
\hline Dictador & 7,14 & 39,62 & 45,45 & 52,27 & 8,82 \\
\hline
\end{tabular}

Fuente: ver nota a pie de página $n^{\circ} 8$

Por último, y más allá del discurso informativo, también nos hemos querido detener en las imágenes que ilustraron el conflicto internacional durante los ocho meses de duración del mismo.

Todos los periódicos analizados incluyen en la mayor parte de las informaciones fotografías sobre el conflicto (gráfico $n^{\circ} 7$ ). Pero además, la mayor parte de estas imágenes respetan la intimidad y honorabilidad de las personas que retratan; solamente el periódico La Vanguardia $y$, en menor medida, El País, recurren a fotografías que pueden vulnerar los derechos fundamentales de las personas.

Se debe señalar también que las imágenes que ilustran el discurso de las informaciones se centran normalmente en el colectivo insurrecto; ello puede a que los periodistas que estuvieron en el conflicto consideraran más relevante retratar la acción del grupo insurgente, ya que, como se ha visto anteriormente, muchas de las noticias iban encaminadas a la visibilización más o menos positiva de su actuación.

\footnotetext{
${ }^{8}$ Pearson $\chi^{2}: 43.313,8, p<.01$
} 


\section{GRÁFICO No 7}

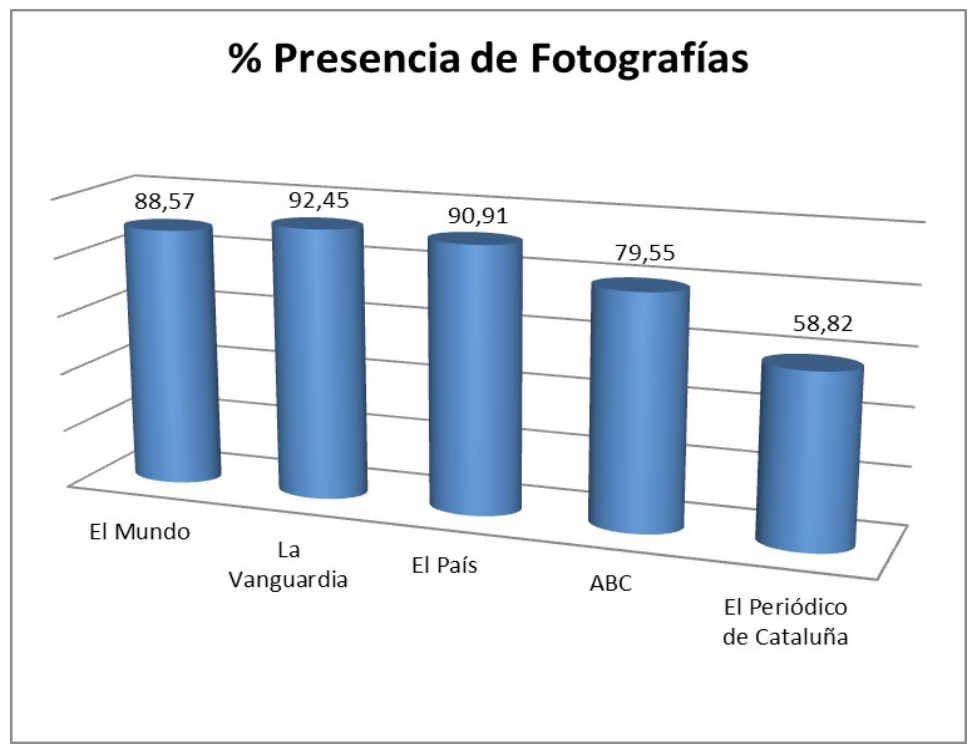

\section{6. ¿Tratamiento informativo homogéneo y objetivo?}

Nuestro análisis ha servido para poner de manifiesto una parte de la cobertura informativa que llevaron a cabo los medios de comunicación en el conflicto internacional de Libia.

Debemos recordar que España cedió las bases militares de Rota y Morón para operaciones internacionales de acción humanitaria y para proteger a la comunidad civil, y que, además, como país miembro de la OTAN, también jugó un papel importante en el terreno.

Es por ello que se ha detectado que hubo una amplia cobertura en los periódicos de referencia nacional, puesto que, desde que comenzó el conflicto, se incluyeron noticias sobre el mismo diariamente, en la sección de internacional.

Ahora bien, en lo que respecta a los fines que perseguía este estudio, podemos decir que se han corroborado todas las hipótesis que se marcaron al inicio de esta investigación, de tal manera que concretamos lo siguiente:

\section{- H1: Hubo un apoyo unánime de los diarios de referencia españoles a las acciones del pueblo libio y una amplia cobertura informativa.}

Se ha comprobado que ha habido, más o menos, un apoyo homogéneo de los periódicos analizados a la comunidad libia, puesto que todos los títulos analizados se han inclinado en la mayor parte de las informaciones por defender un sistema democrático y un clima alejado de la represión en la comunidad libia. 


\section{- H2: La prensa nacional se hizo eco del conflicto de una manera neutral, mediante el uso de diversas fuentes informativas que enriquecen la información.}

También confirmamos esta premisa inicial porque se ha detectado que, independientemente del medio, ha existido cierta pluralidad de enfoques y de fuentes informativas.

Aunque han prevalecido los organismos internacionales, la diplomacia y los gobernantes, también se han tomado como referencia, aunque en menor medida, declaraciones de insurgentes y de aliados de Gadafi. Sin embargo, se ha detectado una menor presencia de ONG y de población civil en el cuerpo de la información.

\section{- H3: El tratamiento informativo y gráfico se realizó de una forma ética, respetando los derechos fundamentales de las personas.}

Hemos determinado que, efectivamente, se ha respetado la imagen de los protagonistas del conflicto, fundamentalmente de la población civil. Se ha mostrado, de manera unánime, un fuerte respeto hacia las víctimas del conflicto armado.

Dicho lo anterior, podemos concluir que el tratamiento informativo por parte de los periódicos de referencia en España estuvo orientado, en cierto modo, a legitimar la acción de la comunidad insurgente, puesto que en la mayor parte de las informaciones de todas las publicaciones se hizo referencia a la necesidad de un sistema democrático, a la libertad o se defendieron los derechos fundamentales de los que el país no goza. En cierto modo, todas las publicaciones científicas que ya han hecho referencia a la llamada Primavera Árabe, coinciden en afirmar que la lucha por el establecimiento de los derechos fundamentales, también en el caso de Libia, contó con apoyos internacionales importantes, tanto de Europa como incluso de EEUU, en el marco de la Resolución 1973 de la ONU (Moscoso del Prado, 2011; Priego, 2011).

Por lo que respecta a las fuentes informativas utilizadas para narrar la guerra civil de Libia, los datos arrojados nos llevan a concluir que, pese a que ha habido cierta pluralidad en la elección de la fuente que construye la información, lo cierto es que han escaseado las narraciones de los propios aliados de Gadafi o de las ONG que protegieron a los más vulnerables. Ello nos puede llevar a determinar que, en cierto modo, los medios pudieron estar algo condicionados por los intereses de la comunidad insurgente, de modo que se convierten en una fuente muy importante de la mayor parte de las informaciones.

El interés de los medios por relatar la posición de las milicias del pueblo llevó a que se obviara la otra parte de la guerra representada por los apoyos del dictador. De este modo, podemos decir que la agenda mediática tuvo tendencia a dejarse llevar por las fuentes de la comunidad insurrecta. Otras investigaciones ya llegaron a esta conclusión para exponer que, en situación de conflicto internacional, los medios defienden al colectivo que lucha por un sistema democrático (Conesa, 1992, Lemieux, 2000, Mercier, 2004). 
En cualquier caso, esta investigación ha puesto de manifiesto que, independientemente de las ideologías que condicionan los discursos de los medios analizados, en todos ellos prevaleció un tratamiento informativo más o menos unánime que defendía la postura del colectivo insurgente y restaba legitimidad a la las acciones de las milicias del dictador.

Podemos decir que los resultados nos han llevado a determinar que el enfoque informativo de los medios fue muy similar, y que el discurso raramente incluyó referencias políticas o interpretaciones subjetivas.

En general, podemos decir que se han hallado posturas neutras en torno a la guerra civil de Libia, si bien debemos tener claro que la mayor parte de las informaciones analizadas adquirieron el formato de noticia; raramente hemos encontrado reportajes o entrevistas, por lo que la tendencia se ha orientado hacia la imparcialidad y la unanimidad en torno a la forma y al contenido de las noticias que hablaban de una lucha por la liberación del pueblo libio. 


\section{BIBLIOGRAFÍA}

ADAY, S.: "Chasing the Bad News: An Analysis of 2005 Iraq and Afghanistan War Coverage on NBC and Fox News Channel", Journal of Communication, vol. 60, issue 1 pp. 144-164, 2010.

AMIRAH, H.: "El regreso de Libia: entre el cambio y el continuismo", en Análisis del Real Instituto Elcano (ARI), n. 58, pp. 1-8, 2006.

BANDURA, A. Social foundations of thought and action, Englewood Cliffs, NJ: Prentice-Hall, 1986.

ALESSANDRI, F.: "Un conflicto bélico y periodístico", en Cuadernos de Información, n. 11, 1996.

CANEL, M. J.: "El País, ABC y El Mundo: tres manchetas, tres enfoques de las noticias", en ZER: Revista de estudios de comunicación, n. 6, 1999.

CASTELLS, M. (2008): "Comunicación, poder y contrapoder en la sociedad red (I). Los medios y la política", en Telos: Cuadernos e comunicación e innovación, n. 74, 2008.

CATALBAS, D.: "Rival discourses of the "war on terror": Afganistán an Iraq wars in the opinión columns of liberal and Islamis newspaper in Turkey", en Global Media and Communication, vol. 7, 3, pp. 275-279, 2011.

COLOMÉ, G.: Política y medios de comunicación, una aproximación teórica. Barcelona, Institut de Ciences Politiques i Socials, 1994.

CONESA, P. (1992): "Analyse stratégique de l'information", en G. Chalianda. La persuasión de masse. Guerre psychologique, guerre médiatique, pp. 87-144, Ediciones Robert Laffont, Paris, 1992

COOPER, S.: "News media objectivity: How do we ask the questions?, en New Jersey Journal of Communication, vol. 2, issue 2, pp. 91-106, 2009.

EDY, J.; MEIRICK, P.: "Wanted, Dead or Alive, Media Frames, Frame Adoption and Support for the War in Afganistan", en Journal of Communication, vol., 57, 1, pp. 119-141, 2007.

ERJAVEC, K.; VOLCIC, Z.: "Mapping the Notion of 'Terrorism' in Serbian and Croatian Newspapers", en Journal of Communication Inquiri, vol. 30, 4, pp. 298- 318, 2006.

FERNÁNDEZ, M.E.: "La responsabilidad de proteger a debate", en Cuadernos electrónicos de filosofía del derecho, n. 22, pp. 76-113, 2011. 
GARCÍA, M. J.: "Mecanismos básico de la propaganda de Guerra en los medios informativos: El ejemplo de Kosovo", en Ámbitos: Revista internacional de comunicación, n. 7-8, pp. 137-149, 2002.

http://0-www.tandfonline.com.jabega.uma.es/action/doSearch? action=runSearch\&type=advanced \&result=true \&prevSearch=\%2Bauthorsfield\%3A \%28Cooper\%2C+Stephen\%29

GLASSER, T.L.: "Objectivity preludes responsibility", en The Quill, pp. 120-135, 1984.

GONZÁLEZ SAN RUPERTO, M.: Las guerras de la ex Yugos/avia: Información y propaganda (tesis doctoral), Madrid: Universidad Complutense de Madrid, 2011.

GRUNDMANN, R., SMITH, D., WRIGHT, S.: "National Elites and Transnational Discourses in the Balkan War: A Comparison between the French, German and British Establishment Press", en European Journal of Communication, September 200, vol. 15, 3, pp. 299-320, 2000.

KAUSCH, K: "Sucesiones orquestadas y estabilidad en el mundo árabe", en Documentos de Trabajo FRIDE, n. 104, pp. 1-22, 2010.

KRIPPENDORFF, Klaus: Metodología de análisis de contenido. Teoría y práctica, Barcelona, Ediciones Paidós Ibérica, 1990.

HARTIN, S.; SCHULTZ, S.: "Media Coverage of Political Issues and the Framing of Personal Concerns", en Journal of Communication, vol. 46, 4, pp. 97-115, 2006.

HOLZHAUSEN, D.: "Public Relations practice and political change in South Africa", en Public Relations Review, vol. 31, issue 3, pp. 407-416, 2005.

JACK, I.: "TV coverage of the Libyan crisis is just a snapshot. We need to know more", en The Guardian, 2011.

LEMIEUX, C.: Mauvaise presse. Une sociologie comprehensive du travail journalistique et de ses critiques, Paris, Ediciones Métailié, 2000.

LLAÓ, M.: "Libia, trazas de una Guerra", en El Viejo topo, n² 284, pp. 35-41, 2011.

LÓPEZ, G.: "Estrategias informativas y recepción mediática: la invasión de Iraq de MarzoAbril de 2003", en Aposta: Revista de ciencias sociales, n. 8, 2003.

MANSO, A.: "Las sombras de la epidémica revolución en Libia y el resto de países del Magreb y Maxreq", en Criminología y Justicia, n. 1 (38-47), 2011.

MERCIER, A.: "Guerres et médias: permanences et mutations", en Raisons politiques, n. 13, pp. 97-109, 2004. 
Mercier, A.: Guerres et médias: permanences et mutations. Raisons politiques, 13, pp. 97109, 2004.

MILLER, J.: "Wars and their journalism", en Global Media and Communication, vol. 7, 3, pp. 205-210, 2011.

MITCHELL, M.: "Using emotion in risk communication: The Anger Activism Model", Public Relations Review, Vol. 33, issue 3, pp. 114-119, 2007.

MOSCOSO DEL PRADO, J.: "Ante la primavera árabe", en Escritura pública, n. 69, p.45, 2011.

MOUSTAOUI SRHIR, A.: "La construcción del sujeto y la auto-representación en los discursos de Muaammar Al Gaddafi: Hacia la auto-deslegitimación", En Discurso \& Sociedad, vol. 5, n. 2, pp. 299-332, 2011.

MURRAY, C., PARRY, K., ROBINSON, P., GODARD, P.: "Reporting Dissent in Wartime: British Press, the Anti-War Movement and the 2003 Iraq War", en Euroepan Journal of Communication, vol. 23, 1, pp. 7-27, 2008.

NOHRSTEDT, S., KAITATZI-WHITLOCK, S, OTTOSEN, R., RIEGERT, K.: "From the Persian Gulf to Kosovo. War Journalism and Propaganda", en European Journal of Communication, vol. 15, 3, pp. 383-404, 2000.

O'REGAN, M.: "The Irish press and the Iraq War: Real world cues, news values and the political calibration effect", en International Communication Gazete, vol. 72, 6, pp. 443464, 2010.

POPP, R.K.: "Mass Media and the Linguistic Marketplace: Media, Language, and Distinction", en Journal of Communication Inquiry, vol. 30, 1, pp. 5-20, 2006.

PRIEGO, A.: "La primavera árabe, ¿̇una cuarta ola de democratización", en UNISCI Discusión Papers, n. 26, pp. 1-20, 2011.

QUEREJAZU, A.: "Seguridad internacional y multilateralismo: las organizaciones internacionales y la intervención en Libia", en Colombia Internacional, julio-diciembre (1 11 136), 2012.

ROBINSON, P.; GODDARD, P.; PARRY, K.; MURRAY, C.: "Testing Models of Media Performance in Wartime: U.K. TV News and the 2003 Invasion of Iraq", en Journal of Communication, vol. 59, 3, 534.563, 2009.

ROBERTSON, J. W.: "People's Watchdogs or Government Poodles?: Scotland's National Broadsheets and the Second Iraq War", en European Journal of Communication, vol. 19, 4, pp. 457-482, 2004. 
RUBIO, J. M.: "Opinión pública y medios de comunicación. Teoría de la agenda setting", en Gazeta de antropología, n. 25, 2009.

SABUCEDO, J. M.: Medios de comunicación de masas y conducta política, Madrid, Biblioteca Nueva, 1997.

SACALUGA, J. A.: "La guerra de Libia: lecciones y contradicciones", en Temas para el debate, n. 198, pp. 57-59, 2011.

SENDÍN, J. C.: Problemas asociados a la construcción del africano en los medios de comunicación en España: análisis del tratamiento informativo de la crisis de Ruanda en Televisión Española (tesis doctoral), Madrid: Universidad Rey Juan Carlos, 2006.

SERRANO, Y.; LÓPEZ, W.: "Estrategias de comunicación militar y dinámicas mediáticas: ¿dos lógicas contradictorias", en Diversitas: perspectivas en psicología pp. 269-277, 2008.

VELÁSQUES, C. y GUTIÉRREZ, L.: "En Busca de opciones ante la censura y la autocesura", en Palabra Clave, n. 5, pp. 81-100, 2001.

ZHU, J.; WATT, J.; SNYDER, L.; YAN, J.; JIANG, Y.: "Public issue priority formation: media agenda-setting and social interaction", en Journal of Communication, vol 43, issue 1, pp. 823, 2006. 